\title{
THE FUTURE OF SOCIAL MEDICINE
}

PHILIPR. LEE, MD

\begin{abstract}
The future of social medicine is based on 150 years of history and the rapidly evolving context within which medicine functions in modern societies. There are two views of social medicine. One is based on the vision of Guerin and, particularly, Virchow 150 years ago that: "Doctors are the natural advocates of the poor, and social problems are largely within their jurisdiction." The New York Academy of Medicine's Institute on Social Medicine 50 years ago reflected this broad view. Medicine, however, enamored of the biomedical paradigm and the advances in knowledge through biomedical research, largely abandoned this broad perspective, even as the knowledge about the social, behavioral, and environmental determinants of health was advancing rapidly. A second view of social medicine, and one that has influenced many in the past 30 years, was defined by McKeown and Lowe: "Social medicine is concerned with a body of knowledge and methods of obtaining knowledge appropriate to a discipline. This discipline may be said to comprise (a) epidemiology, and (b) the study of the medical needs of society, or in the contemporary short hand medical care." Social medicine, in my view, includes not only the definition of McKeown and Lowe, but the broader context within which medicine fits in society. The context is changing. The social contract as defined by Bismarck and Beveridge has to be redefined. Just as the New York Academy of Medicine provided the vision of social medicine 50 years ago, the Academy has given us a new vision with the publication of Medicine and Public Health: the Power of Collaboration in 1997. Authored by Dr. Roz Lasker, director of the Academy's Division of Public Health, the book identifies the key changes required by medicine and public health to advance the goals of medicine and public health for the benefit of both individual patients and the population as a whole. The book points the way for the future of social medicine by identifying not only what needs to be done, but also how to do it.
\end{abstract}

Before attempting to reflect on the future of social medicine as the century turns, I want to say a few personal words about Martin Cherkasky because, in addition to the contributions that Dr. Barondess described, he was a role model for many of us outside New York. I first met Martin in 1951 when I was working on an arthritis rehabilitation project under Dr. Edward Lowman's direction at Goldwa-

Dr. Lee is Professor Emeritus and Senior Advisor, School of Medicine, University of California, San Francisco, 1388 Sutter Street, Suite 1100, San Francisco, CA 94109. (E-mail: mikegem@aol.com) 
ter Memorial Hospital. I was then a fellow in Dr. Howard Rusk's Institute of Physical Medicine and Rehabilitation at New York University. As part of the project, I visited many hospitals and nursing homes, as well as the home care program at Montefiore Hospital. Dr. Cherkasky recently had replaced Dr. Bluestone as the director of Montefiore, but I saw him because he had directed the home care program at Montefiore-a pioneering program, by a pioneering physician. Dr. Cherkasky made a lasting impression, at first because of his understanding of the issues related to the care of the chronically ill and later because I was to recognize his great talent as a leader, as a superb manager, and as a compassionate, but tough and very engaged physician in issues related to health care, particularly the care of the elderly, the chronically ill, and the poor. He had the quality that my father felt was most important for a physician-dedication-and he had it in abundance. Not only did Martin lead in reshaping the hospital and medical care landscape in New York, but he also transformed Montefiore, as its director, to a world class medical center, expanding its social medicine program, developing its family health maintenance demonstration, and working with the commissioner of hospitals, Ray Trussel, in establishing the medical school/municipal hospital affiliations after World War II. He continued to play an active and constructive role in the health affairs of New York City until shortly before his death. He was also a leader in international health care, particularly with respect to the displaced and the vulnerable through his work as a member of the Joint Distribution Committee, not only in Israel, but also in Iran, Turkey, Europe, and Africa.

His ideas had great influence on many of us who went to Washington in the 1960s to change the world and one of us who returned in 1993 with more modest goals. In both cases, while serving as the assistant secretary of health, I recruited a Martin Cherkasky colleague-first George Silver and more recently Jo Ivey Boufford-not only because of their ideas and experience, but also because they shared Martin's values, and both had a deep commitment to the poor, the vulnerable, the underserved, and the disadvantaged. They both served as the conscience of the department. Dr. Cherkasky's influence continues-now through succeeding generations as those he trained, inspired, and worked with have trained a third generation. He was a remarkable man.

I dwell so long on Martin Cherkasky because the symposium not only honors his life and work, but also because he did so much to shape the way we should think about social medicine in the US at the turn of the century. Martin Cherkasky's lifelong concern was with the poor, the disadvantaged, and the oppressed, a concern he showed in thoughts, words, and deeds, qualities shared by the 
founders of social medicine and the New York Academy of Medicine 150 years ago. The origins of social medicine were described by Professor Donald Madison in his introduction to the 20th anniversary report of the Department of Social Medicine, School of Medicine, University of North Carolina, Chapel Hill. He wrote:

And in Social Medicine 1993, I recounted several of the connotations (and aliases) that the term "social" medicine has carried since Jules Guerin, Rudolph Virchow and other physicians participating in the political revolutions of 1848 first used it to underscore their conviction that medicine should address the human misery brought about by industrialization. ${ }^{1}$

Dr. George Rosen ${ }^{2}$ has also described this early history in some detail. The founders of social medicine not only had a broad view of medicine's role in society, but also took action on their beliefs.

\section{MARTIN CHERKASKY AND SOCIAL MEDICINE IN NEW YORK CITY}

Doctor Martin Cherkasky began his rise to prominence in American medicine after World War II in New York City, which was a leader in creative ideas and actions at that time. In 1947, the New York Academy of Medicine celebrated its centennial with an Institute on Social Medicine, with the presented papers published in $1949 .^{3}$

The Family Health Maintenance Demonstration at Montefiore Hospital began in 1950 as part of the Montefiore Medical Group. Its origins, however, could be traced to the Peckham experiment in London, the work of Sidney Kark and his Institute of Family and Community Health in South Africa, as well as the ideas of such innovators in group practice as Dr. George Bachr in New York City. The Milbank Memorial Fund and the Community Services Society of New York were also to play critical roles. ${ }^{4}$ This was a period of great ferment and innovation in New York City; Martin Cherkasky was at the center of it.

Martin Cherkasky's career began to take shape as the United Kingdom began to implement the recommendations of the 1942 Beveridge Report, creating the National Health Service in 1948. Beveridge proposed that Britain attack the "five giant evils of want, disease, ignorance, squalor, and idleness" with a comprehensive system of social insurance for all citizens as a right. ${ }^{1(17)}$ The importance of William Beveridge to social medicine was described succinctly by Dr. Donald Madison in his elegant introduction to the report marking the second decade of the faculty of social medicine at the School of Medicine, University of North Carolina. He wrote:

What makes William Beveridge a major figure in the history of social medicine is that he placed medical care policy in the context of a more general social policy. He saw the NHS 
as a practical expression of the ethic of solidarity, born of the war, but chosen by the British people in the post-war years to replace an older social morality ethic they realized was outmoded. ${ }^{1(\mathrm{p} 18)}$

This broad view was also reflected in Howard Reid Craig's introduction to the New York Academy of Medicine 1949 volume on social medicine:

It is perhaps more important still for medicine to fully realize that it is an integral, interrelated, and independent part of a functioning social and economic system, which to be viable must exist in a continuing state of flux. ${ }^{1(\mathrm{p} 8)}$

In the years immediately after the Academy's Institute on Social Medicine and the publication of the volume edited by Dr. Galdston, medicine turned increasingly inward and away from this broader view. Enamored of the progress made within the context of the biomedical paradigm, medicine was concerned increasingly with the applications of biomedical research to the diagnosis and treatment of individual patients. This loss of the broad perspective, even in the face of the growing body of knowledge about the determinants of health, is one of the reasons that social medicine did not become a mainstream discipline in the years after World War II, a period often described as the "golden age" of medicine. Medicine became more and more specialized and less and less able to recognize that, if you were able to deal with more than the biological determinants of health and apply this knowledge effectively, you had to work with a broad range of people, professions, organizations, and institutions.

\section{OTHER PIONEERS}

My own views about social medicine have been shaped not only by Virchow, Beveridge, Cherkasky, and the New York Academy report, but also by other pioneers, including Cecil Sheps, Jack Geiger, George Rosen, George Silver, Milton Roemer, Julius Richmond, Lester Breslow, Russel Lee, and, perhaps most important, Tom McKeown, who served as professor of social medicine at the University of Birmingham in England for many years. While many have contributed to the advances in our knowledge of social medicine in the past 50 years, two people stand out for me: Lester Breslow and Tom McKeown.

Lester Breslow and his colleagues and students-including Michael Marmot, Leonard Syme, and Lisa Berkman-have contributed greatly to our understanding of the behavioral and social determinants of health.

Tom McKeown and his colleague C. R. Lowe, professor of social and occupational medicine, Welsh National Medical School, Cardiff, wrote the finest book on social medicine since the Academy's volume. Their book, An Introduction to Social Medicine, ${ }^{5}$ was first published in 1966, with a second printing in 1968 and a second edition in 1974 . This book was, for me, a major work in the field. The 
only drawback for a North American was the focus in one section of the book on medical care in the United Kingdom. Milton Roemer's book, Social Medicine: The Advances of Organized Health Services in America, ${ }^{6}$ a compilation of 38 papers written or presented in the 1960s and 1970s, helped to fill that gap. Drs. McKeown and Lowe had a clear vision of the use of the term social medicine. They did not use it in the broader sense used by the New York Academy of Medicine and the early pioneers, but rather they noted:

Social Medicine is concerned with a body of knowledge and methods of obtaining knowledge appropriate to a discipline. This discipline may be said to comprise (a) epidemiology, and (b) the study of the medical needs of society, or in the contemporary shorthand, medical care. ${ }^{5}$

While they did not use the words prevention and policy in this definition, these ideas were very much part of their approach.

\section{THE FUTURE}

In looking at the future of social medicine, we would do well to adopt the perspective reflected in McKeown and Lowe's An Introduction to Social Medicine. First, their assessment of improvements in health drew heavily from Tom McKeown's earlier work. Much of this became the foundation for our current thinking about the determinants of health. They reviewed the measurement of ill health-a continuing challenge.

The second part of their book dealt with "means," including control of inheritance; control of personal measures, including immunization, screening, and modification of personal behavior; control of environment, including nutrition, food-borne disease, water-borne disease, animal-borne disease, atmospheric pollution, the home, and the workplace. All of these are relevant to prevention, as well as the future health, of individuals and populations and the role of medicine.

The final section focused on health and social services, and more specifically on the United Kingdom. Here, the broader context is public policy.

Social medicine, in my view, includes not only the precise definition of McKeown and Lowe, but also the broader context within which medicine fits in society. In this respect, I share Madison's view, summarized so well by Rosen, ${ }^{2}$ and those described so eloquently by Leon Eisenberg at this symposium.

That context is changing, not only in the US, but also in the other industrially advanced societies and in many of the newly emerging nations. In reflecting on the changes of the past 20 years in his editorial, "Prospects for Health Policy," in the journal Health Policy, Professor Jan Blanpain wrote in 1993:

A new social contract is required. Individuals and social responsibilities have to be realigned. Solidarity between generations, reigns, social classes, gender and between the 
healthy and the sick has to be redefined. The Bismarck and Beveridge social contract aimed at providing a social safety net and at preventing individual bankruptcy. Eventually society's capacity and preparedness to support high levels of expenditure for health and social services diminished. Not only has the current system become unaffordable but since it is basically financed by employee and employer contributions, social security changes have developed into major leverage mechanisms creating unemployment. ${ }^{7}$

The challenge is a profound one, but it provides medicine with a unique opportunity for leadership. We must learn the lessons of the past 150 years and understand that social medicine failed to become a mainstream field of scholarship and action. We must also learn the lessons of today.

There is no better source of vision and practical advice on the future of social medicine than the New York Academy of Medicine. With its landmark publication in 1997 of Medicine and Public Health: the Power of Collaboration, ${ }^{8}$ written by Dr. Roz Lasker, director of the Academy's public health division, the Academy again has given us a guide to the future. It is clear in this book, as it was in 1947, that medicine must see itself within a larger social context and not as an isolated, biomedically driven profession. A key to progress in the future-for both medicine and public health-will be the collaboration between these two sectors. Medicine and public health no longer can consider themselves in isolation. They must function together within the context of their roles in the broader community. They can do this without altering their mission or identities.

The lessons learned from the Academy's medicine and public heath project and communicated so clearly in Medicine and Public Health: the Power of Collaboration, is social medicine at its best. The most important lesson is that we can work together to advance the goals of both medicine and public health for the benefit of both individual patients and the population as a whole. The Pocket Guide to Cases of Medicine and Public Health Collaboration documents that these types of partnerships are not hypothetical, but are, in fact, happening all around the country. ${ }^{9}$

Social medicine will continue to contribute to our understanding of the determinants of health and how best to apply that knowledge, whether of human biology, behavior, socioeconomic status, the environment, medical care, or public health, if it continues to carry out such studies, communicates the findings broadly, and provides technical assistance to those throughout the country who are grappling with the issues identified by McKeown and Lowe 30 years ago. The word synergy was used by Dr. Lasker and her colleagues to describe the combinations of resources and skills that constituted the more than 400 models of medical and public health collaboration that they studied throughout the country. Synergy is used in this context to describe the result of collaborative 
efforts in which the whole exceeds the sum of individual efforts. They classified the models of medicine and public health collaboration in six different synergies, ranging from improving health care for individuals to shaping the future direction of the health system by collaborating around policy, training, and research.

\section{CONCLUSION}

The key to the future of social medicine is not in applying a narrow biomedical perspective to the role of medicine in society, but rather in a collaborative approach-a partnership with many other professions, organizations, and institutions. We must look at the examples around us, examples of communities working together. Social medicine in the future will fail as it has in the past 50 years unless we learn this lesson.

Many factors contribute to social medicine not becoming part of the mainstream, including a policy context that has rewarded physicians for focusing on the biological determinants of health and on the development and implementation of biomedical interventions.

To deal with the environmental, social, economic, and behavioral determinants of health, physicians cannot practice social medicine alone. They must be part of a collaborating team drawn from a broad range of health professionals and community groups. Consequently, partnerships are required to advance the most important goals of social medicine. The New York Academy of Medicine now is playing a leading role in identifying how these types of partnerships can be achieved. The partnerships described in the Academy's recent publications represent the evolution of social medicine to a form that has the potential to become not only effective, but also mainstream, in the 21st century.

A critically important role for social medicine in the future will be not only to train physicians in epidemiology, but also to prepare physicians to play important roles in these partnerships and in their communities. Indeed, social medicine as a collaborative effort may be the most important legacy of a symposium honoring the life and works of Martin Cherkasky.

\section{REFERENCES}

1. Madison DL. Introduction: where medicine and society meet. In Social Medicine, 20th anniversary report of the Department of Social Medicine, School of Medicine, University of North Carolina. Chapel Hill, NC: University of North Carolina; 1998:718.

2. Rosen G. What is social medicine? A genetic analysis of the concept. Bull Hist Med. 1947;21:674-733.

3. Galdston I, ed. Social Medicine: Its Derivations and Objectives: The New York Academy of Medicine Institute of Social Medicine, 1947. New York: New York Academy of Medicine; 1949. 
4. Silver GA. Family Medical Care. A Report on the Family Health Maintenance Demonstration. Cambridge, Mass: Harvard University Press; 1963.

5. McKeown T, Lowe CR. An Introduction to Social Medicine. 2nd ed. London: Blackwell Scientific Publications; 1974.

6. Roemer MI. Social Medicine. The Advances of Organized Health Services in America. Vol. 3. New York: Springer; 1978.

7. Blanpain J. Prospects for health policy. Health Policy. 1993;26:2-3.

8. Lasker RD. Medicine and Public Health: the Power of Collaboration. New York: New York Academy of Medicine; 1997.

9. Division of Public Health, New York Academy of Medicine. Pocket Guide to Cases of Medicine and Public Health Collaboration. New York: New York Academy of Medicine; 1997. 